\title{
ŽEMĖS PLUTOS ERDVINIŲ DEFORMACIJU NUSTATYMAS TAIKANT GPS MATAVIMŲ DUOMENIS
}

\author{
Algimantas Zakarevičius, Arminas Stanionis \\ Geodezijos ir kadastro katedra, Vilniaus Gedimino technikos universitetas, \\ Saulètekio al. 11, LT-10223 Vilnius, Lietuva, \\ el.paštas:gkk@ap.vtu.lt
}

Iteikta 200609 03, priimta 20060921

\begin{abstract}
Santrauka. Erdvinès Žemès plutos deformacijos įvertintos baigtinų elementų metodu, deformacijoms nustatyti sudarytas skaičiavimo algoritmas. Eksperimentiniai tyrimai atlikti Ignalinos atominès elektrinès geodinaminio poligono teritorijoje. Gauti nauji erdvinių Žemès plutos deformaciju parametrai - erdvinès santykinès linijinès bei šlyties deformacijos. Tyrimo rezultatai rodo, kad erdvinèms Žemès plutos deformacijoms būdinga tam tikri dèsningumai, t. y. Žemès plutos judesiai Ignalinos atominès elektrinès rajone yra diferencijuoti pagal blokus šiaurinị ir pietini.
\end{abstract}

Reikšminiai žodžiai: baigtinių elementų metodas, erdvinès Žemės plutos deformacijos, GPS.

\section{Ivadas}

Vertikalieji ir horizontalieji Žemès plutos judesiai paprastai nagrinejami atskirai.

Horizontaliosios Žemès deformacijos ir jų savybès tam tikroje teritorijoje tiriamos analizuojant geodeziniu tinklų punktų koordinačių ar kitų elementų pokyčius, nustatytus atliekant kartotinius geodezinius matavimus [1-6]. Pagal šiuos duomenis galima apibūdinti horizontaliąsias Žemès plutos deformacijas, atsiradusias per laiko intervalą tarp kartotinių matavimu, nustatyti jų pobūdị. Kadangi geodezinių tinklų elementų pokyčiai yra susiję su tinklo punktų tarpusavio padèties pakitimais, tai pradiniai duomenys Žemès plutos deformacijoms nustatyti gaunami apdorojant geodezinių tinklų matavimų rezultatus.

Vertikaliujų Žemès plutos deformacijų charakteristikos dažniausiai ivvertinamos taikant niveliacijos metu gautus matavimo rezultatus [7].

Tačiau pastaruoju metu, taikant naujas geodezinių tinklų matavimų technologijas, dažniausiai globalinès padèties nustatymo sistemas (GPS), galima sudaryti didelio tikslumo erdvinius geodezinius tinklus. Turint tokių tinklų kartotinių matavimų duomenis įmanoma iqvertinti erdvines Žemès plutos deformacijas. Pirmosios tokios rekomendacijos pateiktos [8] darbe.

Darbo tikslas - sudaryti erdvinių Žemès plutos deformacijų ìvertinimo algoritmą, erdvines deformacijas ivertinant baigtinių elementų metodu tenzorinès analizès būdu, bei apskaičiuoti Žemès plutos erdvinių deformacijų parametrus Ignalinos atominės elektrinės rajone.

Tyrimams atlikti pasirinktas Ignalinos atominès elektrinès geodinaminis poligonas, nes elektrinè pastatyta stambių tektoninių struktūrų Mozūrijos - Baltarusijos anteklizès, Baltijos sineklizès ir Latvijos balno sandūroje. Kristaliniame paviršiuje išskiriamos žemesniosios eilès tektoninès struktūros: šiaurinė Zarasų pakopa, rytinis Drūkšių grabenas, Anisimovičiu grabenas, Drūkšių ilinkis ir pietinis Drūkšių pakilimas [9].

\section{Erdvinių deformacijų skaičiavimo metodika}

Erdvines Žemès plutos deformacijų charakteristikas galima ivvertinti mažiausiujuc kvadratų metodu [10], taikant laisvojo taškų poslinkio tolygiai besideformuojančioje trimatèje erdvèje modeli [11].

Taškų poslinkių modelis

$$
\Delta E=H \cdot T,
$$

čia

$$
\Delta E=\left[\begin{array}{c}
\Delta X_{1} \\
\Delta Y_{1} \\
\Delta Z_{1} \\
\vdots \\
\Delta X_{i} \\
\Delta Y_{i} \\
\Delta Z_{i} \\
\vdots \\
\Delta X_{n} \\
\Delta Y_{n} \\
\Delta Z_{n}
\end{array}\right]
$$




$$
H=\left[\begin{array}{cccccccccc}
1 & 0 & 0 & -Y_{S_{1}} & X_{S_{1}} & 0 & 0 & Y_{S_{1}} & Z_{S_{1}} & 0 \\
0 & 1 & 0 & X_{S_{1}} & 0 & Y_{S_{1}} & 0 & X_{S_{1}} & 0 & Z_{S_{1}} \\
0 & 0 & 1 & 0 & 0 & 0 & Z_{S_{1}} & 0 & X_{S_{1}} & Y_{S_{1}} \\
\vdots & \vdots & \vdots & \vdots & \vdots & \vdots & \vdots & \vdots & \vdots & \vdots \\
1 & 0 & 0 & -Y_{S_{i}} & X_{S_{i}} & 0 & 0 & Y_{S_{i}} & Z_{S_{i}} & 0 \\
0 & 1 & 0 & X_{S_{i}} & 0 & Y_{S_{i}} & 0 & X_{S_{i}} & 0 & Z_{S_{i}} \\
0 & 0 & 1 & 0 & 0 & 0 & Z_{S_{i}} & 0 & X_{S_{i}} & Y_{S_{i}} \\
\vdots & \vdots & \vdots & \vdots & \vdots & \vdots & \vdots & \vdots & \vdots & \vdots \\
1 & 0 & 0 & -Y_{S_{n}} & X_{S_{n}} & 0 & 0 & Y_{S_{n}} & Z_{S_{n}} & 0 \\
0 & 1 & 0 & X_{S_{n}} & 0 & Y_{S_{n}} & 0 & X_{S_{n}} & 0 & Z_{S_{n}} \\
0 & 0 & 1 & 0 & 0 & 0 & Z_{S_{n}} & 0 & X_{S_{n}} & Y_{S_{n}}
\end{array}\right],
$$

\section{Erdvinių Žemės plutos deformacijų skaičiavimo rezultatai}

$$
T=\left[\begin{array}{c}
\alpha_{X} \\
\alpha_{Y} \\
\alpha_{Z} \\
\omega \\
\varepsilon_{X X} \\
\varepsilon_{Y Y} \\
\varepsilon_{Z Z} \\
\varepsilon_{X Y} \\
\varepsilon_{X Z} \\
\varepsilon_{Y Z}
\end{array}\right],
$$

Ignalinos atominès elektrinès rajone $1998 \mathrm{~m}$. irengtas specialus GPS tinklas (žr. punktu išdèstymo schema). Tinkle yra 10 gruntiniu punktų. Jie išdèstyti atsižvelgiant $\mathfrak{i}$ svarbiausiuju tektoniniu blokų dabartini tektonini aktyvumą. Keturi punktai nuo elektrinès nutolę iki $10 \mathrm{~km}$ spinduliu, kiti yra kelių dešimčiu kilometru atstumu.

Matavimai geodinaminiame poligone atlikti 1998 ir 1999 m. rugsèji. Geodinaminio poligono punktu koordinates nustatytos GPS matavimais [13]. Matuota ASHTECH Z-Surveyor ir Z-12 GPS prietaisais. Matavimus atliko VGTU ir Danijos firmos „Nellemann \& Bjørnkjær" specialistai. Matavimu programą sudare 4 sesijos. Vienos sesijos trukmè - 24 valandos. Visas keturias sesijas buvo matuojama 1, 2, 4, 6, 9, 10 gruntiniuose punktuose, o dvi sesijas $-3,5,7$ ir 8 gruntiniuose punktuose. Matavimu programa pateikta [3, $5,13]$ darbuose.

Punktų koordinačių pokyčiai [13], gauti atlikus GPS

- punktu erdviniu koordinačiu pos vektorius, $H$ - punktų erdvinių koordinačiu nuokrypių nuo jų vidurkio matrica, $T$ - erdvinių Žemés plutos deformacijų parametrų vektorius.

I (1-4) įeinančios reikšmès:

$\Delta X_{i}=X_{i}^{\prime}-X_{i}, \Delta Y_{i}=Y_{i}^{\prime}-Y_{i}, \Delta Z_{i}=Z_{i}^{\prime}-Z_{i}, X_{i}, Y_{i}$, $Z_{i}$ - pirmojo matavimo erdvinès stačiakampès geocentrinès geodezinio tinklo punktu koordinatès, $X_{i}^{\prime}$, $Y_{i}^{\prime}, \quad Z_{i}^{\prime}$ - antrojo matavimo erdvinès stačiakampès geocentrinès geodezinio tinklo punktu koordinatès, $i=1,2, \ldots n$ - punktu numeriai, $X_{S_{i}}, Y_{S_{i}}, Z_{S_{i}}-$ erdvinio geodezinio tinklo punktų koordinačių nuokrypiai nuo jų vidurkio, $\alpha_{X}, \alpha_{Y}, \alpha_{Z}$ - poslinkiai koordinačiu ašiu kryptimis, $\omega$ - baigtinio elemento posūkis, $\varepsilon_{X X}$, $\varepsilon_{Y Y}, \varepsilon_{Z Z}$ - santykinès linijinès deformacijos, $\varepsilon_{X Y}, \varepsilon_{X Z}$, $\varepsilon_{Y Z}$ - santykinès šlyties deformacijos.

Mažiausiujų kvadratų metodu įvertintas erdvinių deformacijų parametrų vektorius [12]

$$
T=\left(H^{T} \cdot H\right)^{-1} \cdot H^{T} \cdot \Delta E
$$
matavimus $1998 \mathrm{~m}$. rugsèji ir $1999 \mathrm{~m}$. rugsèji, pateikti 1 lentelèje.

Pagal (2-5) formules ivertinta penkiu geodinaminio poligono trikampių erdvinių deformaciju parametrų kaita (̌̌r. pav.): apskaičiuoti poslinkiai koordinačiu ašiu kryptimis, posūkiai, santykinès linijinès bei šlyties deformacijos. Erdviniu deformaciju parametrai priskiriami baigtinio elemento (trikampio) svorio centrui.

Erdviniai Žemès plutos deformaciju parametrai pagal GPS matavimų duomenis apskaičiuoti naudojantis Mathcad programa.

Gautieji erdvinių Žemès plutos deformaciju parametrų vektoriai pateikti 2 lentelèje.

Santykinių linijinių deformaciju $\varepsilon_{X X}$ kitimo ribos nuo $-0,323 \cdot 10^{-6}$ iki $-0,972 \cdot 10^{-6}, \quad \varepsilon_{Y Y}$ kinta nuo $-0,125 \cdot 10^{-6}$ iki $0,604 \cdot 10^{-6}$ bei $\varepsilon_{Z Z}$ kinta nuo $-0,438 \cdot 10^{-6}$ iki $1,065 \cdot 10^{-6}$ (2 lentelè). Santykinès šlyties deformacijos $\varepsilon_{X Y}$ kinta nuo $-0,482 \cdot 10^{-6}$ iki $0,517 \cdot 10^{-6}, \varepsilon_{X Z}-$ nuo $-0,171 \cdot 10^{-6}$ iki $0,650 \cdot 10^{-6}$, $\varepsilon_{Y Z}-$ nuo $-0,476 \cdot 10^{-6}$ iki $0,645 \cdot 10^{-6}$ (2 lentelè). 

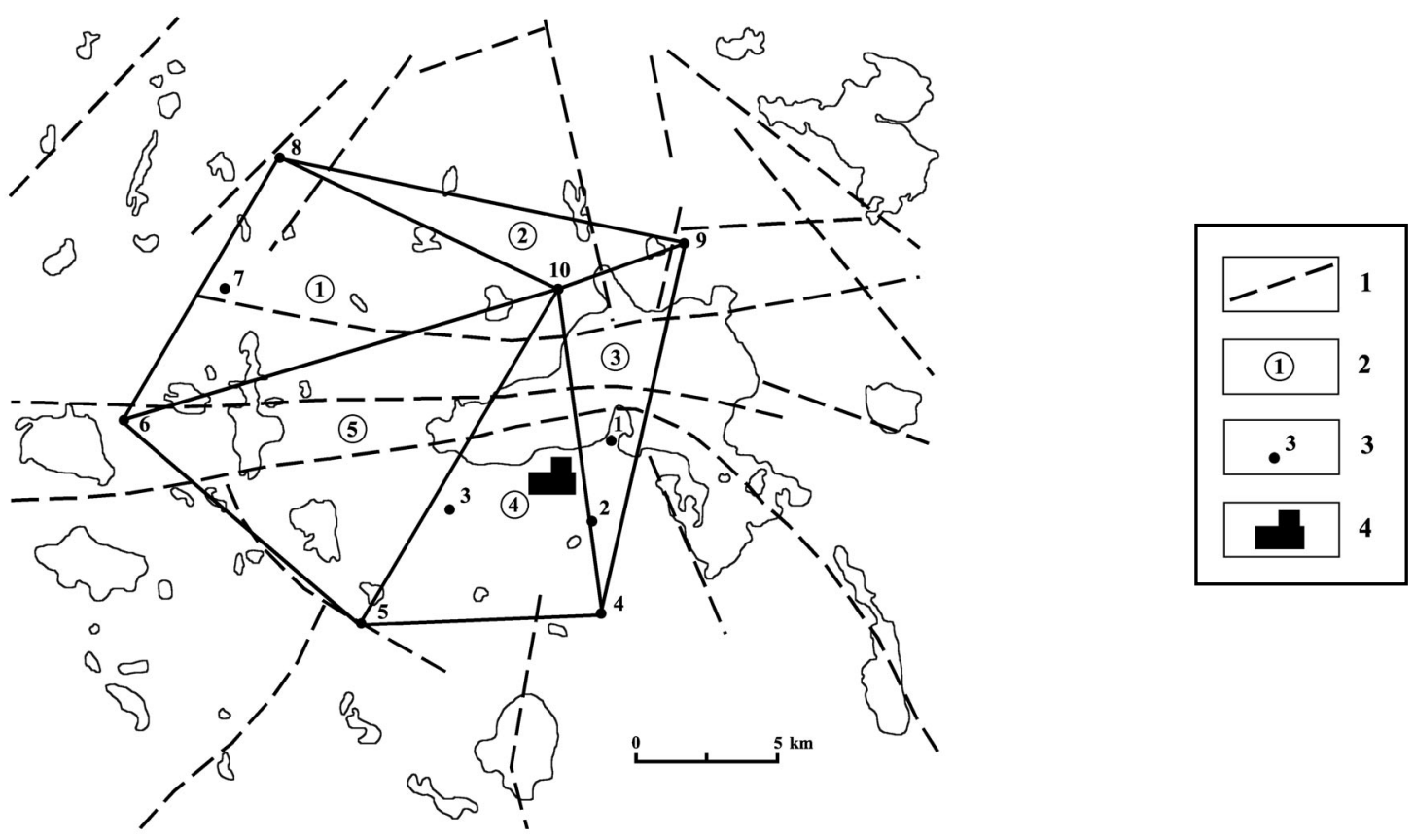

Baigtinių elementų tinklo schema Ignalinos atominès elektrinès rajono teritorijoje: 1 - tektoniniai lūžiai (sudarè P. Suveizdis), 2 trikampio numeris, 3 - GPS punktas, 4 - Ignalinos atominè elektrinè

The location scheme of the network of the finite elements at the Ignalina Nuclear Power Plant: 1 - tectonic breaks (according to P. Suveizdis), 2 - number of triangles, 3 - GPS benchmarks, 4 - Ignalina NPP

1 lentelè. Punktų koordinačiu pokyčiai

Table 1. Changes of benchmark coordinates

\begin{tabular}{|c|c|c|c|c|c|c|c|}
\hline Punkto Nr. & $\Delta X(\mathrm{~mm})$ & $\Delta Y(\mathrm{~mm})$ & $\Delta Z(\mathrm{~mm})$ & Punkto Nr. & $\Delta X(\mathrm{~mm})$ & $\Delta Y(\mathrm{~mm})$ & $\Delta Z(\mathrm{~mm})$ \\
\hline 1 & 8 & 1 & 1 & 6 & 8 & 2 & -3 \\
\hline 2 & 0 & 1 & 2 & 7 & 11 & -2 & 1 \\
\hline 3 & 1 & 0 & 0 & 8 & 14 & -3 & -3 \\
\hline 4 & 1 & 2 & -2 & 9 & 7 & -1 & 1 \\
\hline 5 & 3 & 0 & 0 & 10 & 8 & 0 & 0 \\
\hline
\end{tabular}

2 lentelè. Deformacijų parametrai

Table 2. Parameters of deformations

\begin{tabular}{|c|c|c|c|c|c|c|c|c|c|c|}
\hline $\begin{array}{l}\text { Trikam- } \\
\text { pio Nr. }\end{array}$ & $\begin{array}{c}\alpha_{X X} \\
\text { (m) }\end{array}$ & $\begin{array}{l}\alpha_{Y Y} \\
\text { (m) }\end{array}$ & $\begin{array}{l}\alpha_{Z Z} \\
(\mathrm{~m})\end{array}$ & $\omega^{\prime \prime}$ & $\begin{array}{l}\varepsilon_{X X} \\
\cdot 10^{-6}\end{array}$ & $\begin{array}{l}\varepsilon_{Y Y} \\
\cdot 10^{-6}\end{array}$ & $\begin{array}{l}\varepsilon_{Z Z} \\
\cdot 10^{-6}\end{array}$ & $\begin{array}{l}\varepsilon_{X Y} \\
\cdot 10^{-6}\end{array}$ & $\begin{array}{l}\varepsilon_{X Z} \\
\cdot 10^{-6}\end{array}$ & $\begin{array}{l}\varepsilon_{Y Z} \\
\cdot 10^{-6}\end{array}$ \\
\hline 1 & 0,0100 & $-0,0003$ & $-0,0020$ & 0,162 & $-0,972$ & 0,435 & $-0,438$ & 0,019 & $-0,171$ & 0,213 \\
\hline 2 & 0,0097 & $-0,0013$ & $-0,0007$ & 0,216 & $-0,323$ & 0,604 & 1,065 & 0,517 & 0,650 & 0,645 \\
\hline 3 & 0,0053 & 0,0003 & $-0,0003$ & 0,117 & $-0,358$ & 0,130 & 0,770 & $-0,145$ & 0,048 & 0,296 \\
\hline 4 & 0,0040 & 0,0007 & $-0,0007$ & 0,049 & $-0,796$ & 0,174 & $-0,094$ & $-0,482$ & $-0,133$ & $-0,476$ \\
\hline 5 & 0,0063 & 0,0007 & $-0,0010$ & 0,067 & $-0,658$ & $-0,125$ & $-0,049$ & $-0,173$ & $-0,052$ & 0,314 \\
\hline
\end{tabular}

Remiantis tyrimų rezultatais (2 lentelè) Ignalinos atominès elektrinès rajone pastebimi tam tikri erdvinių Žemès plutos judesių pasiskirstymo dèsningumai. Jie yra susiję su teritorijos tektonine sandara.

Poslinkiai $\alpha_{X X}$ yra teigiami, poslinkiai $\alpha_{Y Y}$ pasiskirsto pagal beveik paralelès kryptimi einanti ir rytinejje poligono dalyje $i$ pietryčius pasisukanti kristalinio pamato Drūkšių lūži, t. y. šiauriniame bloke poslinkiai neigiami (1 ir 2 trikampiai), o pietiniame teigiami $\left(3,4\right.$ ir 5 trikampiai), $\alpha_{Z Z}-$ neigiami. Santykinès linijinès deformacijos $\varepsilon_{X X}$ yra neigiamo ženklo, $\varepsilon_{Y Y}-$ teigiamos (išskyrus 5 trikampi). Santykinès šlyties deformacijos $\varepsilon_{X Y}$ pasiskirsto pagal blokus, 
nustatytus vertikaliujų judesių tyrimais [4], t. y. šiauriniame bloke deformacijos yra teigiamos, pietiniame neigiamos.

Turint geodezinio tinklo erdvines deformacijas galima ivertinti erdvinius geodezinių tinklų ittempių pokyčius.

Taikant siūlomą skaičiavimo metodiką erdvinėms Žemès plutos deformacijoms nustatyti gali būti panaudoti kartotiniai horizontaliujų bei vertikaliujų geodezinių tinklų matavimų duomenys, t. y. plokštuminio geodezinio tinklo punktų koordinačių bei tų pačių punktų aukščių pokyčiai.

\section{Išvados}

1. Sudarytas erdvinių Žemès plutos deformacijų skaičiavimo algoritmas, deformacijas ivvertinant baigtinių elementu metodu tenzorinès analizès būdu, bei atlikti eksperimentiniai skaičiavimai Ignalinos atominès elektrinès rajone pagal geodezinių matavimų duomenis.

2. Gauti nauji erdvinių Žemès plutos deformacijų parametrai - apskaičiuoti poslinkiai koordinačiu ašių kryptimis, trikampio posūkiai, erdvinès santykinès linijinès bei šlyties deformacijos.

3. Tyrimu rezultatai koreliuoja su anksčiau atliktu vertikaliuju bei horizontaliuju judesių tyrimu Ignalinos atominès elektrinès rajone duomenimis. Poligono teritorijoje Žemès plutos judesiai išsiskiria pagal beveik paralelès kryptimi einantị ir rytineje poligono dalyje $i$ pietryčius pasisukanti kristalinio pamato Drūkšiu lūžị, t. y. skirtingais būdais atliktų tyrimų rezultatai atspindi tuos pačius dèsningumus.

\section{Literatūra}

1. Hamdy, A. M.; Park, P. H.; Lim, H. C. Horizontal deformation in South Korea from permanent GPS network data, 2000-2003. Earth Planets and Space, Vol 57, No 2. Terra Scientific Publishing Company, 2005, p. 77-82.

2. Kaiser, A.; Reicherter, K.; Hübscher, C.; Gajewski, D. Variation of the present-day stress field within the North German Basin-insights from thin shell FE modeling based on residual GPS velocities. Tectonophysics, Vol 397, No 1-2. Elsevier Science Publishers B. V., 2005, p. 55-72.

3. Stanionis, A. Research of the Earth's crust horizontal movements in the Ignalina nuclear power plant region by geodetic methods. Summary of Doctoral Dissertation. Vilnius: Technika, 2005. 24 p.

4. Zakarevičius, A. Investigation of the recent geodynamic processes in the territory of Lithuania (Dabartiniu geodinaminiu procesu Lietuvos teritorijoje tyrimas). Vilnius: Technika, 2003. 195 p. (in Lithuanian).

5. Zakarevičius, A.; Aksamitauskas, Č.; Stanionis, A. Modelling of the horizontal strains and stresses of the Earth-crust according to the data of geodetic measurements. Geodetski vestnik, Vol 49, No 2. Ljubljana, 2005, p. 191-207.
6. Zakarevičius, A.; Stanionis, A. Modelling the horizontal movements and deformations of the Earth crust by the finite element method. Geodesy and Cartography (Geodezija ir kartografija), Vol XXX, No 2. Vilnius: Technika, 2004, p. 35-40 (in Lithuanian).

7. Zakarevičius, A. The investigation of present vertical Earth crust's movements in the territory of Lithuania (Dabartiniu vertikaliuju Žemès plutos judesių Lietuvos teritorijoje tyrimas). Vilnius: Technika, 1994. 276 p. (in Lithuanian).

8. Zakarevičius, A. Estimation of the tensors and parameters of the space deformations of the Earth's crust. Geodesy and Cartography (Geodezija ir kartografija), Vol XXVI, No 1, 2000, p. 39-42 (in Lithuanian).

9. Tectonic structure of Lithuania (Lietuvos tektonine sandara). Compiled and edited by P. Suveizdis. Institute of Geology and Geography, Vilnius, 2003. 160 p. (in Lithuanian).

10. Zienkiewicz, O. C.; Taylor, R. L. The finite element method. Vol 1. Fifth edition. Butterworth-Heinemann, 2000. 689 p.

11. Niemeier, W.; Rennen, M.; Salbach, H. Bestimmung der regionaler und globaler Deformationen im Bereich der Antarktischen Halbinsel. Deutsche Beiträge zu GPSKampagnen des Scientific Committee on Antarctic Research (SCAR), Heft Nr. 310. München: Verlag der Bayerischen Akademie der Wissenschaften in Kommission bei der C. H. Beck'schen Verlagsbuchhandlung, 2000, S. 109-126.

12. Zakarevičius, A.; Stanionis, A. The dispersion structure of horizontal deformations of Lithuanian geodetic networks. Geodesy and Cartography (Geodezija ir kartografija), Vol XXVIII, No 4, Vilnius: Technika, 2002, p. 117-124 (in Lithuanian).

13. Ignalina control network, Lithuania - second campaign. Final report. Rambøll, September 2000. 64 p.

\footnotetext{
Algimantas ZAKAREVIČIUS. Professor, Doctor Habil. Dept of Geodesy and Cadastre, Vilnius Gediminas Technical University, Saulètekio al. 11, LT-10223 Vilnius, Lithuania (tel. +370 5274 4703), e-mail:

Algimantas.Zakarevicius@ap.vtu.lt.

A graduate of Kaunas Polytechnic Institute (now Kaunas University of Technology), geodetic engineer, 1965. Doctor's degree at Vilnius University, 1973. Dr Habil degree at VGTU, 2000. Member of the Geodetic Commission of Estonia, Latvia and Lithuania. Research training at Geodetic Institute of Norwegian Mapping Authority, 1994. Author of over 140 publications and 3 monographs.
}

Research interests: investigations of the recent geodynamic processes, formation of geodetic networks.

Arminas STANIONIS. Associate Professor, Doctor. Dept of Geodesy and Cadastre, Vilnius Gediminas Technical University, Sauletekio al. 11, LT-10223 Vilnius, Lithuania (tel. +370 5274 4703), e-mail: Arminas.Stanionis@ap.vtu.lt.

A graduate of Vilnius Gediminas Technical University (VGTU) (Master of science, 2002). Doctor's degree at VGTU, 2005. Author and co-author of 18 publications.

Research interests: investigation of geodynamic processes, GIS, investigations of deformations. 